\title{
Cardiogenic refractory hypoxaemia secondary to blunt chest trauma: diagnosis by transoesophageal echocardiography
}

\author{
F Chirillo, O Totis, A De Leo
}

\begin{abstract}
A 53 year old man suffered severe head and blunt chest trauma as a result of a fall (from four metres high). On arrival at the emergency room he was unconscious with hypovolaemic circulatory shock. Following orotracheal intubation and resuscitation with blood, inotropic agents, and crystalloid, he was transferred to the neurosurgical intensive care unit. Analysis of arterial blood gases revealed a $\mathrm{PaO}_{2}$ of $50 \mathrm{~mm} \mathrm{Hg}, \mathrm{PaCO}_{2} 35 \mathrm{~mm} \mathrm{Hg}$, and $\mathrm{pHa} 7.47$. Increase in $\mathrm{FIO}_{2}$ up to 1.0 did not result in any increase in $\mathrm{PaO}_{2}$. Ventilation with positive end expiratory pressure made the hypoxaemia more severe. Pulmonary embolism was excluded by lung scintigraphy, mild right pulmonary contusion was evident on computed tomography; pneumothorax was not evident using chest radiography. Central venous pressure was $13 \mathrm{~mm} \mathrm{Hg}$, mean pulmonary artery pressure $21 \mathrm{~mm} \mathrm{Hg}$, pulmonary wedge pressure $15 \mathrm{~mm} \mathrm{Hg}$, and cardiac index $2.30 \mathrm{l} / \mathrm{min} / \mathrm{m}^{2}$. Cardiac shunting was suspected and transoesophageal echocardiography (TOE) was performed.
\end{abstract}

TOE showed dilated right atrium and right ventricle. The anterior tricuspid leaflet looked partially avulsed from the annulus; neither valve prolapse nor ruptured chordae were evident. The tricuspid regurgitant jet origi- nated just below the atrioventricular groove and looked relatively narrow at the origin becoming noticeably larger in the right atrium just above the tricuspid leaflets (fig 1). The regurgitant jet was eccentric and directed towards the atrial septum (fig 1). Here a large tear $(2.6 \mathrm{~cm})$ was seen in the region of the septum primum (fig 2). The regurgitant jet originating from the tricuspid valve entered the left atrium through the ruptured atrial septum producing a large right-to-left shunting. Surgical repair of the incompetent tricuspid valve and closure of the atrial septal defect led to significant improvement.

\section{Discussion}

Blunt chest trauma may cause severe hypoxaemia by a variety of mechanisms. ${ }^{1}$ The most common cause of right-to-left shunting is intrapulmonary functional shunt as a consequence of severe parenchymal pulmonary disease such as cardiogenic and noncardiogenic pulmonary oedema, pneumonia, atelectasis, and pulmonary embolism. In all but the last situation chest radiography usually reveals significant lung abnormalities. In trauma patients the most frequent mechanism of right-to-left intracardiac shunting is increased right atrial pressure following

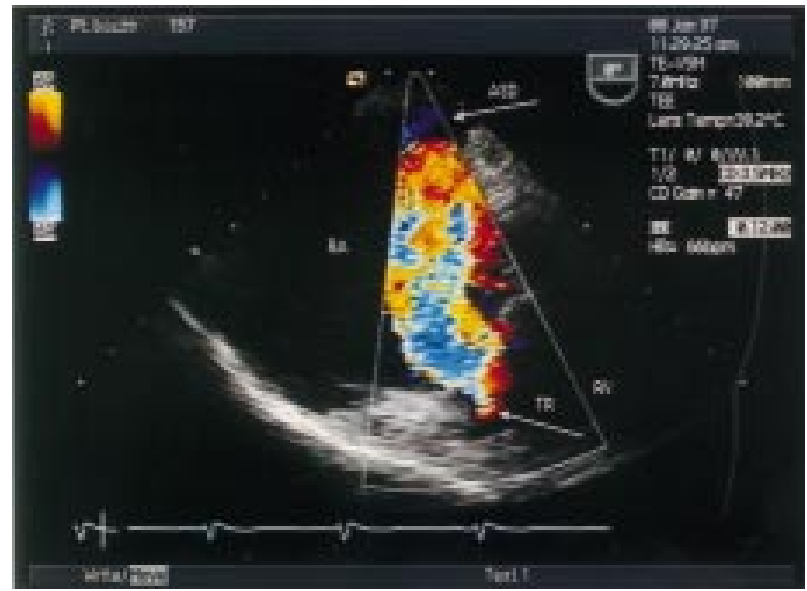

Figure 1 Colour Doppler transoesophageal echocardiography showing severe tricuspid regurgitation originating from the ruptured anterior leaflet. The regurgitant jet is eccentric and directed towards the traumatic atrial septal defect. ASD, atrial septal defect; $R A$, right atrium; $R V$, right ventricle; TR, tricuspid regurgitation.

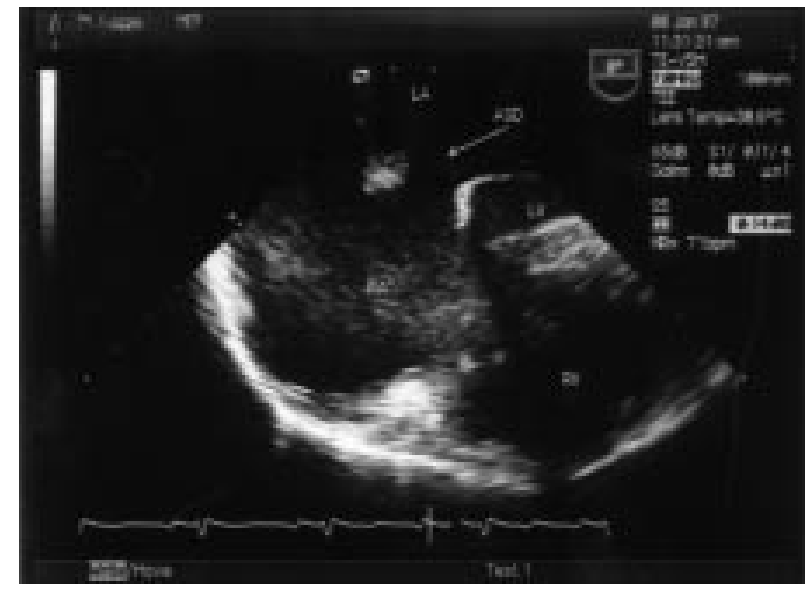

Figure 2 Transoesophageal four chamber view demonstrates a large atrial septal defect in the region of the septum primum. ASD, atrial septal defect; $L A$, left atrium; $R A$, right atrium; $R V$, right ventricle. 
mechanical ventilation with positive end expiratory pressure, forcing the foramen ovale to open. $^{23}$ The magnitude of the shunt in our patient was greater than that usually observed under these circumstances and was the result of three factors: (1) the septal defect was significantly larger than those observed in presence of patent forame ovale; (2) the right atrial pressure was increased because of the severity of the tricuspid valve regurgitation; (3) the tricuspid regurgitant jet was eccentric and directed towards the caudal portion of the atrial septum where the septal tear was located. Colour Doppler TOE demonstrated the regurgitant jet entering the left atrium through the ruptured atrial septum. This streaming effect may have contributed to increase the right-toleft shunting, considering the relatively increased mean right atrial pressure.
We report this case to remind those dealing with the management of patients with blunt chest trauma that there are causes of severe, refractory hypoxaemia outside the lung. In this situation TOE, when performed by skilled operators, is an invaluable diagnostic tool $^{4}$ because it can provide accurate diagnosis of cardiac injuries in a short time at the bedside.

1 Fraser GF, Pare JAP, Pare PD, et al. Diagnosis of diseases of the chest. 3rd ed. Philadelphia: WB Saunders Company, 1988. 2 Konstad SN, Louie EK, Black S, et al. Intraoperative detection of patent forame ovale by transesophageal echocardiography. Anesthesiology 1991;74:212-16.

3 Haussman D, Muegge A, Becht I, et al. Diagnosis of patent Haussman D, Muegge A, Becht I, et al. Diagnosis of patent
forame ovale by transesophageal echocardiography and association with cerebral and peripheral embolic events. Am F Cardiol 1992;70:668-72.

4 Chirillo F, Totis O, Cavarzerani A, et al. Usefulness of transthoracic and transoesophageal echocardiography in recognition and management of cardiovascular injuries after blunt chest trauma. Heart 1996;75:301-6.

\section{IMAGES IN CARDIOLOGY}

\section{Primary angioplasty and stenting of left main coronary occlusion}

A 56 year old male smoker with a one year history of hypertension presented with a two hour history of severe, tight, central chest pain. Examination revealed that he was sweating profusely and had cold peripheries. His blood pressure was $90 / 60 \mathrm{~mm} \mathrm{Hg}$ and auscultation of the chest revealed evidence of pulmonary oedema. The electrocardiogram showed sinus rhythm with broadening of the QRS complexes and widespread ST/T wave changes suggestive of cardiac ischaemia, but not fulfilling conventional criteria for thrombolysis. He was treated with aspirin, diamorphine, and intravenous heparin, and transferred to the cardiac catheter laboratory where angiography demonstrated proximal thrombotic occlusion of the left main coronary artery (A). The right coronary was ectatic, with no flow-limiting stenosis and there was some retrograde collateral filling of the left coronary.

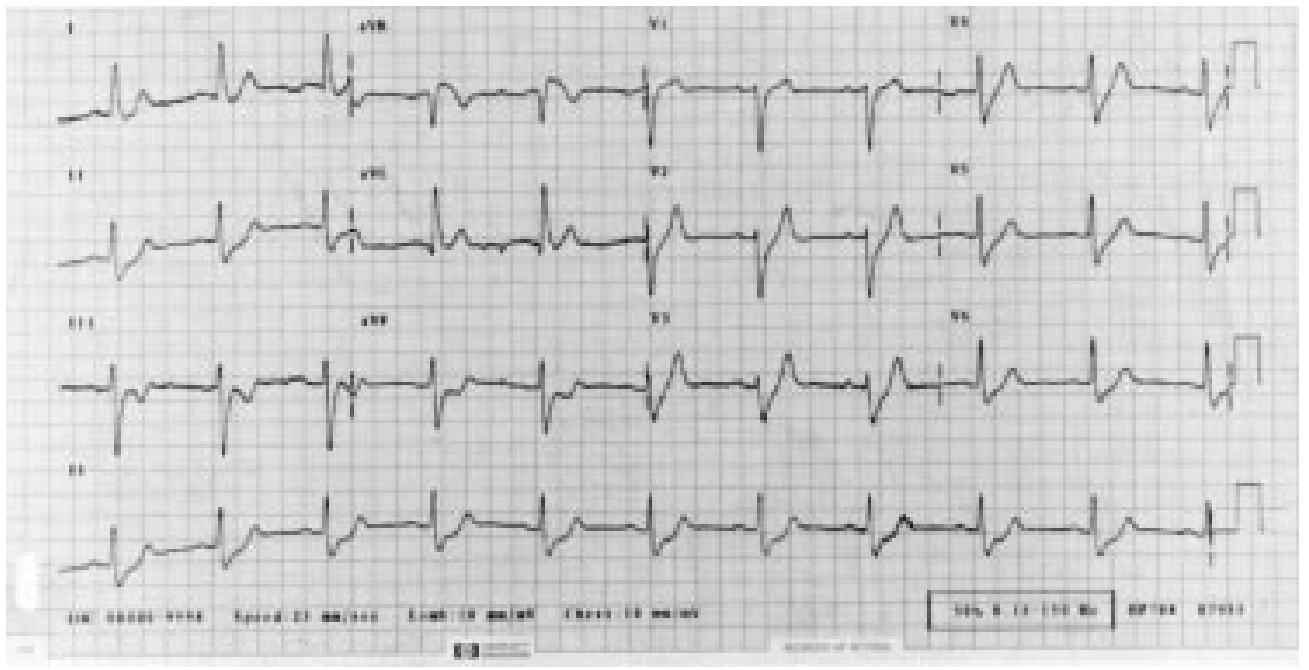




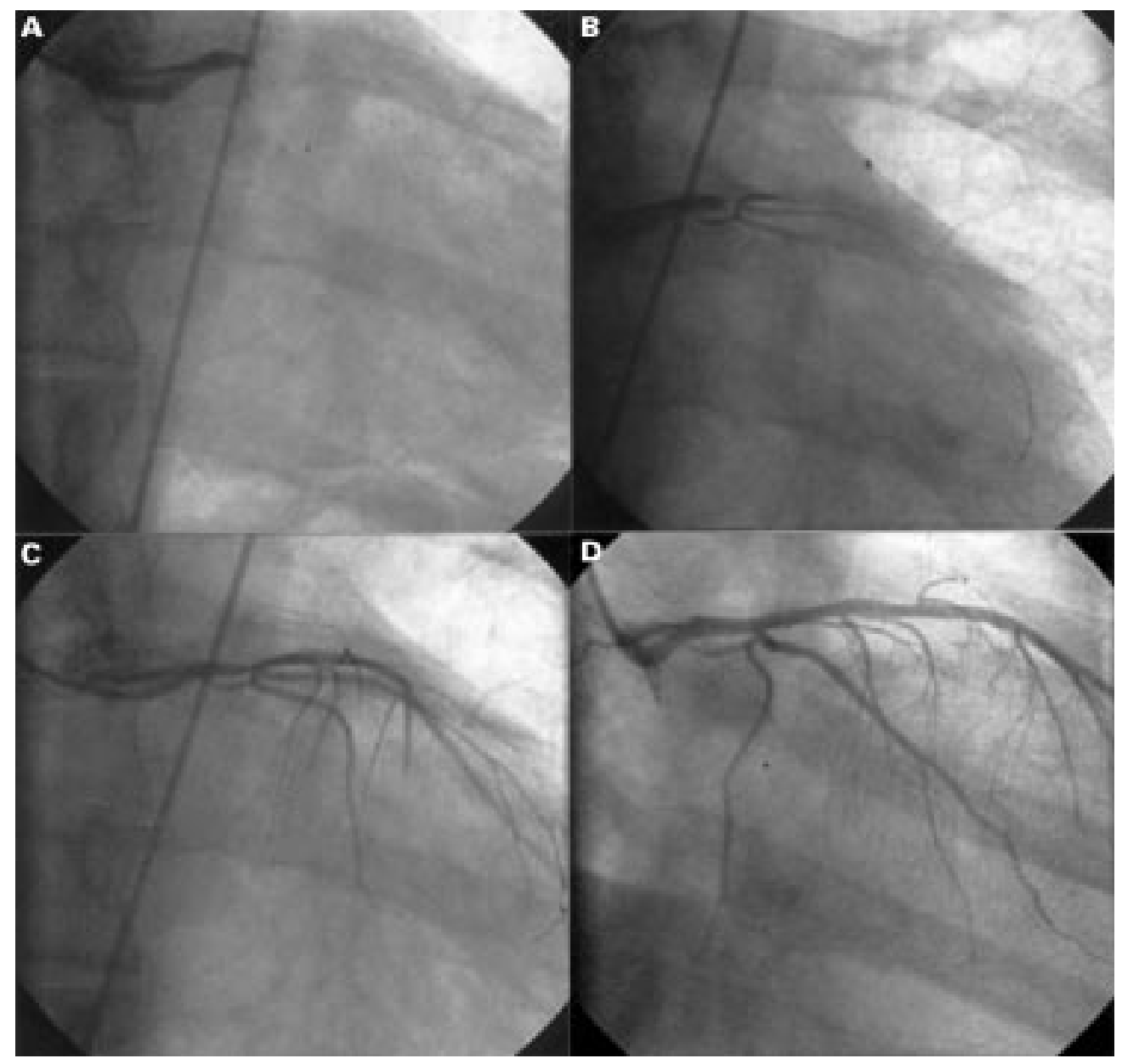

After discussion with the cardiac surgeons, insertion of an intra-aortic balloon pump, and administration of abciximab, a guidewire was passed through the occlusion with some immediate improvement in antegrade flow (B). Balloon angioplasty resulted in improved flow but as there was some residual stenosis (C). A $16 \mathrm{~mm}$ Multilink intracoronary stent (Guidant ACS, Basingstoke, UK) was inserted with an excellent angiographic result (D). He was started on ticlopidine and the balloon pump was removed 36 hours after the procedure. Predischarge angiography confirmed persistence of the excellent angiographic result and a left ventricular ejection fraction of approximately $40 \%$. At follow up eight weeks later he was asymptomatic on medical treatment (angiotensin converting enzyme inhibitor, diuretic, and aspirin).

A P BANNING 